\title{
Chapter 4 \\ Rethinking the Infodemic: Social Media and Offline Action in the COVID-19 Pandemic
}

\author{
Leonardo W. Heyerdahl, Benedetta Lana, and Tamara Giles-Vernick
}

\begin{abstract}
In parallel with the COVID-19 pandemic, an infodemic - an information epidemic — challenges human populations across the planet. Often framed as an enemy to be conquered, infodemics endanger public health because inaccurate or erroneous information spreads quickly on a large scale, triggers potentially harmful behaviours, and generates stress and anxiety. Much infodemics research privileges the investigation of online information creation and circulation, as well as measures to counter erroneous information. Less examined, however, are the offline effects of an infodemic. This chapter surveys how infodemic analysts have evaluated interactions between online information and offline practice. It examines studies focusing on the harmful content of the online informational ecosystem and containment efforts, and then explores social sciences contributions, which broadly identify factors contributing to public interpretation and offline practices. We conclude with a concrete example of an anthropological study exploring the interplay of online information and offline practice during the COVID-19 pandemic.
\end{abstract}

Keywords Infodemic $\cdot$ COVID-19 $\cdot$ Social media $\cdot$ Red Cross

\section{Introduction}

In parallel with the COVID-19 pandemic, an infodemic - an information epidemicchallenges human populations across the planet. Characterized as "excessive" and rapidly. disseminating information that unintentionally or intentionally misleads the public about diverse aspects of the pandemic (Ratzan et al. 2020; Sharma et al. 2020), the infodemic is often framed as an enemy to be conquered. It endangers public health because inaccurate or erroneous information spreads quickly on a large scale, triggers potentially harmful behaviours, and generates profound stress and anxiety. From 2020, this infodemic appears to have catalyzed distrust and denial of COVID-19, uses of dangerous or ineffective remedies, and the destruction of telecommunications

L. W. Heyerdahl · B. Lana · T. Giles-Vernick $(\bowtie)$

Anthropology and Ecology of Disease Emergence Unit, Institut Pasteur, Paris, France

e-mail: tamara.giles-vernick@pasteur.fr

M. Yano et al. (eds.), Socio-Life Science and the COVID-19 Outbreak, Economics, Law, and Institutions in Asia Pacific, https://doi.org/10.1007/978-981-16-5727-6_4 
towers based on claims linking $5 \mathrm{G}$ networks with viral transmission (Biasio et al. 2020; Dubey et al. 2020; Gallotti et al. 2020; Naeem et al. 2020). Little wonder, then, that WHO Director-General Tedros Adhanom Ghebreyesus said of the COVID19 pandemic: "We're not just fighting an epidemic; we're fighting an infodemic. Fake news spreads faster and more easily than this virus and is just as dangerous" (Zarocostas 2020).

Infodemics are complex phenomena, emerging in part from online information that is disseminated through diverse media available to publics, and from the interconnectedness and deregulation of the world wide web. Social media platforms and their public data offer useful and illuminating opportunities for studying informational dynamics on a large scale (Ceron et al. 2014; Greco and Polli 2019; Pelagalli et al. 2017). This opportunity, then, has led many infodemics researchers to privilege investigating online information creation, circulation, and change. Less examined, however, are the offline effects of an infodemic. Specifically, in focusing on online informational dynamics, infodemics specialists have attended far less to how lay publics interpret excessive, rapidly circulating information, how they make decisions about that information, and how their decisions translate into harmful behaviours. Indeed, as anthropologist Meg Stalcup has observed about the Zika infodemic in Brazil, it is frequently assumed that "what happens on social media ramifies in actions and feelings" (Stalcup 2020 p.10), without careful attention to the processes by which this takes place.

In this chapter, we survey how infodemic analysts have evaluated interactions between online information and offline practice. We begin by examining investigations that focus on the harmful content of the online informational ecosystem and containment efforts. We then examine the social sciences contributions, which broadly identify factors contributing to public interpretations and their offline practices. We conclude with a concrete example of an anthropological study exploring the interplay of online information and offline practice during the COVID-19 pandemic.

\section{Rumours, Fake News, Conspiracy Theories, and Other Online Content}

Infodemiology, "the science of distribution and determinants of information in an electronic medium, specifically the Internet, or in a population, with the ultimate aim to inform public health and public policy", principally analyzes and ultimately seeks to manage online content. Emerging in the early 2000s as a multidisciplinary field, infodemiology developed rapidly over the following two decades, evaluating rapidly circulating information so as to facilitate effective public health management of online information (Eysenbach 2002, 2009). Infodemiology studies, for instance, have tracked rumours and fake news during the first SARS outbreak and the Ebola and Zika epidemics (Anwar et al. 2020; Safarnejad et al. 2020; Stalcup 2020). 
A second branch of investigation, infoveillance, monitors health-related information that is promulgated by mass and social media, and it highlights distinctions between misinformation (misleading information, but not deliberately designed to manipulate) and disinformation (information deliberately developed or spread to manipulate users) Confronted with expanding "fake news", public health specialists have employed infoveillance investigations to understand better the place of readers and users in spreading information (Bunker 2020; Gallotti et al. 2020; Pulido et al. 2020); to trace the activities of social media companies, TV channels, newspapers and public authorities in regulating the information arena (Donovan 2020; Mackey et al. 2020; Naeem et al. 2020); and to evaluate the impact and diffusion of specific information (Islam et al. 2020; Rovetta and Bhagavathula 2020).

In parallel with this expansion of infoveillance to monitor and regulate media platform content, risk communication studies have developed guidelines and communications techniques for actors to convey official messages. Their techniques range from limiting the negative effects of pre-prints, preliminary observations, and other unreviewed information (Casigliani et al. 2020), to calling for more responsible, scientifically-grounded, journalism (Anwar et al. 2020), to designing appealing social media posts that relay information and attract the readers' attentions (King and Lazard 2020).

These infodemic and infoveillance studies all address the supply of information, in that they focus first on information quality (evidence-based, derived from reliable sources) to achieve effective public health management and, second, on containing misinformation or disinformation. At times, supply-oriented management can involve the deletion of reports, claims, or advice designated as misinformation or misinformation. In the past year, two infodemic management frameworks, one by the World Health Organization and a second from infodemiology field founder Gunther Eysenbach, have integrated both dimensions of information quality and mis/disinformation containment (Eysenbach 2020; Tangcharoensathien et al. 2020). The underlying assumption of these reports is that online users, provided with appropriate content, would be well-informed and thus would comply with correct guidelines and measures relating to COVID-19.

Moreover, these frameworks are anchored by a further assumption about official, authoritative messages to be communicated to lay publics: that alternative messages challenge this authority. Infodemics thus constitute a security issue and must be controlled. Yet at the heart of this assumption is a fundamental problem. In a pandemic caused by a new and rapidly changing pathogen, where scientific and public health knowledge are rapidly changing, what is "true" or "false"? Is it possible to delineate clearly what types of knowledge should be monitored, controlled or censored? (Marin 2020; Southwell et al. 2019).

In contrast to these supply-oriented approaches that would channel accurate information to users, demand-oriented approaches seek to educate users in health literacy so that they can distinguish between "good" and "bad" information. Over the past decade, health literacy studies have sought to cultivate in diverse populations the capacity to search, select, and appraise health-related information and thus to enhance certain health behaviours (Britt et al. 2017; Lee et al. 2020). COVID-19 health literacy 
studies, for instance, have assessed readers' and users' skills in performing effective searches, understanding information, and adopting health behaviours conducive to good health; they have also recommended strategies to educate publics to select critically and to interpret health advice and information (in the COVID-19 context see, e.g.: Biasio et al. 2020; Okan et al. 2020; Rosário et al. 2020; Sentell et al. 2020). Although the health literacy approach has had its sceptics (Brown et al. 2012; Neter and Brainin 2019), this approach has catalyzed a host of "demand-side" strategies to educate lay publics. Emerging from decades-old social psychological "inoculation theory" (Compton 2013; McGuire 1964), "debunking" demonstrates that specific information is false; "social inoculation", also referred to as "pre-bunking", anticipates misinformation and disinformation by exposing users to weak, deconstructed forms of misinformation, to arm users with the critical skills to identify appropriate information and detect manipulation attempts or gaps in logic. (Compton et al. 2016; Cook et al. 2017; Lewandowsky and Van Der Linden 2021).

These infodemics approaches make important contributions to analyses of information flows and to the design of frameworks for public health management during public health emergencies. But they assume that the quality of information and public awareness of the processes that produce this information determine human behaviours. Insights from other social sciences disciplines, including psychology, anthropology, and history, suggest that complex, interacting factors shape what people believe and do in practice.

\section{How Does an Information Ecosystem Affect Human Practice?}

Efforts to characterize and evaluate the influence that an information ecosystem has on how certain populations feel, think, and act, remain relatively less studied than information ecosystems themselves. Nonetheless, behavioural investigations have figured prominently here, prior to and during the COVID-19 pandemic.

Drawing from psychology, behavioral studies assess the information ecosystem's effects on human psychological states, to illuminate emotional responses to infodemics and to link these responses to specific types of media used (Centola 2010; Doornwaard et al. 2015; Marino et al. 2018; Martínez-Ferrer et al. 2018; Moreno and Whitehill 2014; Saran et al. 2018; Tran et al. 2017). More recently in the COVID19 pandemic, Luo et al. (2020) and Bala et al. (2021) have evaluated the effects of social media exposure on preventive and health behaviours through cross-sectional surveys, concluding that social media platforms offer important health guidance for lay publics, but that information overload can lead to stress and "cyberchondria" (distress caused by excessive consultation of online sites). Another investigation analyzed rumours, stigma, and conspiracy theories related to COVID-19 and accounts of the real-life effects of online news reporting, finding a correlation between infodemics and violence (Islam et al. 2020). Using social listening of Twitter and call logs 
of a US regional poison control centre, Chary and colleagues linked online advice of using bleach as COVID-19 prophylaxis and emergency phone calls for bleach poisoning (Chary et al. 2020).

Although such studies usefully identify psychological effects of online sources and posit compelling correlations with offline behaviour, they leave certain questions unanswered. We have no insight into how actors obtained and interpreted the specific online narratives, nor how they acted on that information. Nor do they address the socio-political logics that may influence a user's choice of information sources or the reasons that the user might seize upon certain misinformation. In addition, because these studies categorize information as true or false, they do not grasp the volatility of medical claims to truth in a pandemic. Knowledge can change rapidly during a pandemic, and as Eysenbach has argued, we are often working with best available evidence rather than stable medical facts (Eysenbach 2020).

Other social scientists have sought to excavate these concerns. Anthropologists and historians take seriously "rumours", considering them to be "more than simply stories which are not true" (Kaler 2009). The term "rumour" itself can be problematic, potentially mobilized by authorities to dismiss stories that they found destabilizing (Geissler and Pool 2006). Yet the contributions of these scholars has been important: they have been less preoccupied by the veracity of claims than in using the claims to better understand specific social groups' perceptions, values, and worldviews (Ceyssens 1975; Fairhead et al. 2006; Geissler and Pool 2006; Graboyes 2015; Kaler 2004, 2009; Scheper-Hughes 2001; Tappan 2014; White 2000). From rumours of blood theft to those of sterility, these stories offer insight into distrust and critique of biomedical research, as well as broader reflections on the plural inequalities inherited from the colonial period. More broadly, field-based qualitative social sciences like anthropology and history situate a social group's specific understandings and practices within their broader socio-cultural, political, and economic contexts (Geissler and Pool 2005).

Although none of the foregoing studies addresses how online claims shape human offline practices, this anthropological insistence of evaluating all online claims, regardless of their veracity, to illuminate how people gather, interpret, and act on such claims have made their way into infodemics research, including that related to the COVID-19 pandemic (Durand and Cunha 2020; Kozinets 2015; Krieg et al. 2017; Larson 2020; Stalcup 2020). In our research in France, too, we are pursuing such an approach. In the Paris region, we investigated whether the COVID-19 infodemic has had any effect on the risk perceptions, engagement in field activities, and protective practices of French Red Cross (FRC) volunteers in the Paris region (Heyerdahl et al. 2021). Specifically, we have tracked Twitter discussions and selected traditional media for seven months, evaluating all claims and debates about non-pharmaceutical protection measures. We also conducted interviews with FRC workers and volunteers. Thus far, although social and traditional media debates about viral risks and non-pharmaceutical interventions appear to aggravate anxieties among FRC volunteers and workers, their decisions to continue Red Cross field activities and daily protection practices like wearing masks appear to be affected by other factors that 
were not related to the infodemic. Familial and social obligations, gender expectations, financial pressures, FRC rules and communications, state regulations, and relations with co-workers all shaped their decisions.

The benefits of this type of approach provides insight into why individuals and social groups do not trust authoritative information sources. Building trust by cultivating dialogue, Heidi Larson (2020) has effectively contended, may do more to facilitate trust than fighting misinformation.

\section{Conclusion}

The COVID-19 infodemic has catalyzed considerable scholarly and public health attention, and the expanding literatures of infodemiology and infoveillance have extended our collective understanding of the dynamics and circulation of claims, stories, and advice—-some true and some not. How this information epidemic shapes human action offline, however, remains less well understood. Drawing insights from anthropology and history to examine how and why social groups seek out and interpret certain claims, stories, and advice, and how they act on them, offers a fruitful avenue for more rigorous and robust tracing of online influences on offline behaviors.

\section{References}

Anwar A, Malik M, Raees V, Anwar A (2020) Role of mass media and public health communications in the COVID-19 Pandemic. Cureus 12(9):e10453. https://doi.org/10.7759/cureus.10453

Bala R, Srivastava A, Ningthoujam GD, Potsangbam T, Oinam A, Anal CL (2021) An observational study in Manipur State, India on preventive behavior influenced by social media during the COVID-19 pandemic mediated by cyberchondria and information overload. J Prev Med Public Health 54(1):22

Biasio LR, Bonaccorsi G, Lorini C, Pecorelli S (2020) Assessing COVID-19 vaccine literacy: a preliminary online survey. Human Vaccines Immunotherapeutics 1-9. https://doi.org/10.1080/ 21645515.2020.1829315

Britt RK, Collins WB, Wilson K, Linnemeier G, Englebert AM (2017) eHealth literacy and health behaviors affecting modern college students: a pilot study of issues identified by the american college health association. J Med Internet Res 19(12):e392. https://doi.org/10.2196/jmir.3100

Brown CW, Shepperson JT, Gopalan H, El-Amin S (2012) HIV: facts, fiction, and the impact on behavior of students at an historically black college/university. Int $\mathrm{J}$ Health Promot Educ 50(2):61-67. https://doi.org/10.1080/14635240.2012.661964

Bunker D (2020) Who do you trust? the digital destruction of shared situational awareness and the COVID-19 infodemic. Int J Info Manage 102201. https://doi.org/10.1016/j.ijinfomgt.2020. 102201

Casigliani V, De Nard F, De Vita E, Arzilli G, Grosso FM, Quattrone F, Lopalco P et al (2020) Too much information, too little evidence: is waste in research fuelling the Covid-19 infodemic? BMJ, 370 m2672. https://doi.org/10.1136/bmj.m2672

Centola D (2010) The spread of behavior in an online social network experiment. Science 329(5996):1194-1197. https://doi.org/10.1126/science.1185231 
Ceron A, Curini L, Lacus SM (2014) Social media e sentiment analysis: l'evoluzione dei fenomeni sociali attraverso la rete. vol 9. Springer Science and Business Media

Ceyssens R (1975) Mutumbula, mythe de l'opprimé. Cultures Et Dévelop 7(3-4):483-550

Chary MA, Overbeek DL, Papadimoulis A, Sheroff A, Burns MM (2020) Geospatial correlation between COVID-19 health misinformation and poisoning with household cleaners in the Greater Boston Area. Clin Toxicol 59(4):320-325

Compton J (2013) Inoculation theory. In: The sage handbook of persuasion: develop theory practice. vol 2. pp 220-237

Compton J, Jackson B, Dimmock JA (2016) Persuading others to avoid persuasion: inoculation theory and resistant health attitudes. Front Psychol 7:122

Cook J, Lewandowsky S, Ecker UK (2017) Neutralizing misinformation through inoculation: exposing misleading argumentation techniques reduces their influence. PloS one 12(5):e0175799

Donovan J (2020) Social-media companies must flatten the curve of misinformation. Nature. https:// doi.org/10.1038/d41586-020-01107-z

Doornwaard SM, Ter Bogt TF, Reitz E, van den Eijnden RJ (2015) Sex-related online behaviors, perceived peer norms and adolescents' experience with sexual behavior: testing an integrative model. PloS one 10(6):e0127787. https://doi.org/10.1371/journal.pone.0127787

Dubey S, Biswas P, Ghosh R, Chatterjee S, Dubey MJ, Chatterjee S, Lavie CJ (2020) Psychosocial impact of COVID-19. Diabetes Metab Syndr 14(5):817-823

Durand JY, Cunha MI (2020) 'To all the anti-vaxxers out there...': ethnography of the public controversy about vaccination in the time of COVID-19. Soc Anthropol

Eysenbach G (2002) Infodemiology: the epidemiology of (mis)information. Am J Med 113(9):763765. https://doi.org/10.1016/S0002-9343(02)01473-0

Eysenbach G. (2009) Infodemiology and infoveillance: framework for an emerging set of public health informatics methods to analyze search, communication and publication behavior on the internet. J Med Internet Res 11(1):e11. https://doi.org/10.2196/jmir.1157

Eysenbach G (2020) How to fight an infodemic: the four pillars of infodemic management. J Med Internet Res 22(6):e21820. https://doi.org/10.2196/21820

Fairhead J, Leach M, Small M (2006) Where techno-science meets poverty: medical research and the economy of blood in the Gambia. West Africa Soc Sci Med 63(4):1109-1120. https://doi.org/ 10.1016/j.socscimed.2006.02.018

Gallotti R, Valle F, Castaldo N, Sacco P, Domenico MD (2020) Assessing the risks of 'infodemics' in response to COVID-19 epidemics. Nature Human Behaviour 1—9. https://doi.org/10.1038/ s41562-020-00994-6

Geissler PW, Pool R (2005) In: Medical anthropology. United Kingdom, McGraw-Hill Education

Geissler PW, Pool R (2006) Popular concerns about medical research projects in sub-Saharan Africa-a critical voice in debates about medical research ethics. Trop Med Int Health 11(7):975982

Graboyes M (2015) The experiment must continue: medical research and ethics in East Africa, 1940-2014. Ohio University Press, Athens, Ohio

Greco F, Polli A (2019) Vaccines in Italy: the emotional text mining of social media. Rivista Italiana Di Economia Demografia e Statistica 73(1):89-98

Heyerdahl LW, Vray M, Leger V, Le Fouler L, Antouly J, Troit V, Giles-Vernick T (2021) Evaluating the motivation of red cross health volunteers in the COVID-19 pandemic: a mixed-methods study protocol. BMJ Open 11(1):e042579

Islam MS, Sarkar T, Khan SH, Kamal A-HM, Hasan SMM, Kabir A, Seale H (2020) COVID-19related infodemic and its impact on public health: a global social media analysis. Am J Trop Med Hyg 103(4):1621-1629. https://doi.org/10.4269/ajtmh.20-0812

Kaler A (2004) The moral lens of population control: condoms and controversies in southern Malawi. Stud Fam Plann 35(2):105-115

Kaler A (2009) Health interventions and the persistence of rumour: the circulation of sterility stories in African public health campaigns. Soc Sci Med 68(9):1711-1719 
King AJ, Lazard AJ (2020) Advancing visual health communication research to improve infodemic response. Health Commun 35(14):1723-1728. https://doi.org/10.1080/10410236.2020.1838094

Kozinets RV (2015) In: Netnography: redefined, SAGE Publications

Krieg LJ, Berning M, Hardon A (2017) Anthropology with algorithms? an exploration of online drug knowledge using digital methods. Med Anthropol Theory 4(3):21-52

Larson HJ (2020) Stuck: how vaccine rumors start-and why they don't go away. Oxford University Press, New York

Lee JJ, Kang K-A, Wang MP, Zhao SZ, Wong JYH, O'Connor S, Shin S (2020) Associations between COVID-19 misinformation exposure and belief with COVID-19 knowledge and preventive behaviors: cross-sectional online study. J Med Internet Res 22(11):e22205-e22205. https:// doi.org/10.2196/22205

Lewandowsky S, Van Der Linden S (2021) Countering misinformation and fake news through inoculation and prebunking. European Rev Soc Psychol 1-38. https://doi.org/10.1080/10463283. 2021

Luo Y, Yao L, Zhou L, Yuan F, Zhong X (2020) Factors influencing health behaviours during the coronavirus disease 2019 outbreak in China: an extended information-motivation-behaviour skills model. Public Health 185:298-305

Mackey TK, Li J, Purushothaman V, Nali M, Shah N, Bardier C, Liang B et al. (2020) Big data, natural language processing, and deep learning to detect and characterize illicit COVID-19 product sales: infoveillance study on twitter and instagram. JMIR Public Health Surveillance 6(3):e20794. https://doi.org/10.2196/20794

Marin L (2020) Three contextual dimensions of information on social media: lessons learned from the COVID-19 infodemic. Ethics Info Technol 1-8. https://doi.org/10.1007/s10676-020-09550-2

Marino C, Gini G, Vieno A, Spada MM (2018) The associations between problematic Facebook use, psychological distress and well-being among adolescents and young adults: a systematic review and meta-analysis. J Affect Disord 226:274-281. https://doi.org/10.1016/j.jad.2017.10.007

Martínez-Ferrer B, Moreno D, Musitu G (2018) Are adolescents engaged in the problematic use of social networking sites more involved in peer aggression and victimization? Front Psychol 9:801. https://doi.org/10.3389/fpsyg.2018.00801

McGuire WJ (1964) Inducing resistance to persuasion. Some contemporary approaches. In Berkowitz L (ed) Advances in experimental social psychology, vol 1. pp 191-229. https://doi. org/10.1016/S0065-2601(08)60052-0

Moreno MA, Whitehill JM (2014) Influence of social media on alcohol use in adolescents and young adults. Alcohol Res 36(1):91-100

Naeem SB, Bhatti R, Khan A (2020) An exploration of how fake news is taking over social media and putting public health at risk. Health Info Libr J. https://doi.org/10.1111/hir.12320

Neter E, Brainin E (2019) Association between health literacy, eHealth literacy, and health outcomes among patients with long-term conditions: a systematic review. Eur Psychol 24:68-81. https:// doi.org/10.1027/1016-9040/a000350

Okan O, Bollweg TM, Berens E-M, Hurrelmann K, Bauer U, Schaeffer D (2020) Coronavirusrelated health literacy: a cross-sectional study in adults during the COVID-19 infodemic in Germany. Int J Environ Res Public Health 17(15). https://doi.org/10.3390/ijerph17155503

Pelagalli F, Greco F, De Santis E (2017) Social emotional data analysis. The map of Europe. In: Petrucci AV, Rosanna (ed) Statistics and data science: new challenges, new generation, pp 779-784

Pulido CM, Villarejo-Carballido B, Redondo-Sama G, Gómez A (2020) COVID-19 infodemic: more retweets for science-based information on coronavirus than for false information. Int Sociol 35(4):377-392. https://doi.org/10.1177/0268580920914755

Ratzan SC, Sommariva S, Rauh L (2020) Enhancing global health communication during a crisis: lessons from the COVID-19 pandemic. Public Health Res Pract 30(2). https://doi.org/10.17061/ phrp3022010 
Rosário R, Martins MRO, Augusto C, Silva MJ, Martins S, Duarte A, Dadaczynski K et al (2020) Associations between COVID-19-related digital health literacy and online informationseeking behavior among portuguese university students. Int J Environ Res Public Health 17(23):8987.https://doi.org/10.3390/ijerph17238987

Rovetta A, Bhagavathula AS (2020) COVID-19-related web search behaviors and infodemic attitudes in Italy: infodemiological study. JMIR Public Health Surveillance 6(2):e19374. https://doi. org/10.2196/19374

Safarnejad L, Xu Q, Ge Y, Bagavathi A, Krishnan S, Chen S (2020) Identifying influential factors in the discussion dynamics of emerging health issues on social media: computational study. JMIR Public Health Surveillance 6(3):e17175. https://doi.org/10.2196/17175

Saran I, Fink G, McConnell M (2018) How does anonymous online peer communication affect prevention behavior? evidence from a laboratory experiment. PloS One 13(11):e0207679. https:// doi.org/10.1371/journal.pone.0207679

Scheper-Hughes N (2001) Commodity fetishism in organs trafficking. Body Soc 7(2-3):31-62. https://doi.org/10.1177/1357034x0100700203

Sentell T, Vamos S, Okan O (2020) Interdisciplinary perspectives on health literacy research around the world: more important than ever in a time of COVID-19. Int J Environ Res Public Health 17(9). https://doi.org/10.3390/ijerph17093010

Sharma DC, Pathak A, Chaurasia RN, Joshi D, Singh RK, Mishra VN (2020) Fighting infodemic: need for robust health journalism in India. Diabetes Metab Syndr 14(5):1445-1447. https://doi. org/10.1016/j.dsx.2020.07.039

Southwell BG, Niederdeppe J, Cappella JN, Gaysynsky A, Kelley DE, Oh A, Chou W-YS (2019) Misinformation as a misunderstood challenge to public health. Am J Prev Med 57(2):282-285. https://doi.org/10.1016/j.amepre.2019.03.009

Stalcup M (2020, 2020/03/16/T18:41:57+00:00). The invention of infodemics: on the outbreak of zika and rumors. Retrieved from files/2959/infodemics-zika.html.html

Tangcharoensathien V, Calleja N, Nguyen T, Purnat T, D'Agostino M, Garcia-Saiso S, Briand S et al (2020) Framework for managing the COVID-19 infodemic: methods and results of an online, crowdsourced WHO technical consultation. J Med Internet Res 22(6):e19659. https://doi.org/10. $2196 / 19659$

Tappan J (2014) Blood work and "Rumors" of blood: nutritional research and insurrection in Buganda, 1935-1970. Int J Afr Hist Stud 47(3):473-494

Tran BX, Huong LT, Hinh ND, Nguyen LH, Le BN, Nong VM, Ho RC et al. (2017) A study on the influence of internet addiction and online interpersonal influences on health-related quality of life in young Vietnamese. BMC Public Health 17(1):138. https://doi.org/10.1186/s12889-0163983-z

White L (2000) Speaking with vampires: rumor and history in colonial Africa. University of California Press, Berkeley, CA

Zarocostas J (2020) How to fight an infodemic. Lancet 395(10225):676. https://doi.org/10.1016/ s0140-6736(20)30461-x

Leonardo W. Heyerdahl is a postdoctoral fellow in the Anthropology \& Ecology of Disease Emergence at the Institut Pasteur. In collaboration with the Red Cross and the European RECOVER project, Leonardo is developing and implementing hybrid methods spanning from computational social science to ethnographic fieldwork to characterize, measure the impact, and act upon infodemics during the COVID-19 pandemic in several European countries. Prior to joining Institut Pasteur, he worked a decade in cholera and Ebola preparedness and response programmes in west, central and eastern Africa. Leonardo holds a doctorate in Social Sciences from the École Normale Supérieure de Lyon, France, a master's degree in Sociology from Université Caen-Basse Normandie, France and a master's degree in Humanitarian \& cultural project management from Université Aix-Marseille, France. 
Benedetta Lana is a research engineer at the Ecology and Anthropology of Emerging Diseases unit of the Pasteur Institute (Paris), where she has contributed to projects focusing on social media listening of Covid-19 discourses in France, in collaboration with the Red Cross and the European RECOVER project. She is currently working on a vulnerability assessment project in relation to the COVID-19 pandemic in France as part of the SoNAR-Global research network. Benedetta holds a master's in Human Rights and Humanitarian Action from Sciences Po Paris, where she specialized in Migrations and African Studies. Her research has focused on ESC rights and their accessibility for people on the move in transit and destination countries.

Tamara Giles-Vernick is Director of Research and Head of the Anthropology and Ecology of Disease Emergence Unit - the Institut Pasteur's first social sciences research unit. Dr GilesVernick currently coordinates SoNAR-Global, a European Commission-funded (Horizon 2020) global social sciences research network for preparedness and response to infectious threats. As part of the SoNAR-Global program, she is coordinating a seven-country investigation of the new forms of vulnerability and complex factors shaping them as a consequence of the COVID-19 pandemic.

A specialist in the medical anthropology and history of central and west Africa, her current research focuses on emerging zoonotic diseases and epidemics. She is conducting a national study for preparedness and response to Ebola UNICEF in the Central African Republic. She also directs the MICROTONE study, which offers a pre-history of zoonotic disease emergence in the Democratic Republic of Congo. She has also led a three-country study on the anthropology, history, and geography of human-non-human primate contact and emerging zoonotic diseases in central Africa. In addition, she has published on viral hepatitis (diagnostics, linkage to care, vaccination), Ebola, Buruli ulcer, the historical emergence of HIV in Africa, global health in Africa, the history of influenza pandemics, and environmental history.

Open Access This chapter is licensed under the terms of the Creative Commons AttributionNonCommercial-NoDerivatives 4.0 International License (http://creativecommons.org/licenses/bync-nd/4.0/), which permits any noncommercial use, sharing, distribution and reproduction in any medium or format, as long as you give appropriate credit to the original author(s) and the source, provide a link to the Creative Commons license and indicate if you modified the licensed material. You do not have permission under this license to share adapted material derived from this chapter or parts of it.

The images or other third party material in this chapter are included in the chapter's Creative Commons license, unless indicated otherwise in a credit line to the material. If material is not included in the chapter's Creative Commons license and your intended use is not permitted by statutory regulation or exceeds the permitted use, you will need to obtain permission directly from the copyright holder.

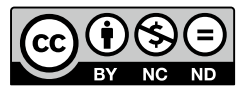

